\title{
Williams Flexion Exercise for Low Back Pain: A Possible Implementation in Rural Areas
}

\author{
William Putera Sukmajaya ${ }^{1 *}$, Firas Farisi Alkaff ${ }^{2}$, Alina Oen $^{3}$, Alverina Cynthia Sukmajaya $^{4}$ \\ ${ }^{1}$ Department of Orthopedics and Traumatology, Saiful Anwar General Hospital-Universitas Brawijaya, Malang, East Java, \\ Indonesia; 'Department of Pharmacology, Faculty of Medicine, Universitas Airlangga, Surabaya, East Java, Indonesia; \\ ${ }^{3}$ Department of Rehabilitation and Physical Medicine, Surabaya Orthopedics and Traumatology Hospital, Surabaya, East Java, \\ Indonesia; ${ }^{4}$ Department of Biomedical Science, Faculty of Medicine, Airlangga University, Surabaya, East Java, Indonesia
}

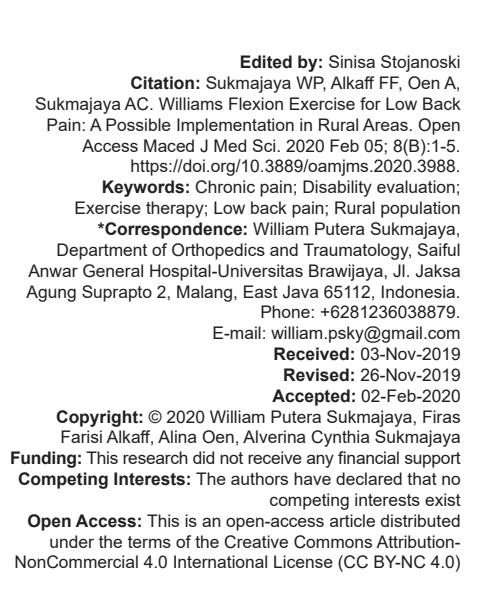

\begin{abstract}
AIM: Low back pain (LBP) is a widespread complaint of all age groups. The economic burden of LBP is high, and physiotherapy has proven to reduce this. Unfortunately, physiotherapy or exercise regimen is rarely prescribed to LBP patients by doctors. Until now, there was no study regarding the application of physiotherapy exercise in Indonesia. This study aims to evaluate the effect of Williams flexion exercise (WFE) toward people with LBP.

METHODS: This was a pretest-posttest experimental study design of PROLANIS participants with LBP complaints in one of the primary health-care centers in Jombang, East Java, Indonesia, on June 2018-July 2018. The tota sampling method was used in this study. Participants' basic clinical data and Oswestry Disability Index (ODI) were obtained through a self-administered questionnaire. WFE was taught to the participants through a presentation, video, and live demonstration. After 1 month, ODI of the participants was reassessed.

RESULTS: There were 42 participants included in this study. There was a significant ODI difference between pre- and post-WFE implementation ( $31.05 \pm 17.40$ vs. $14.10 \pm 11.78, p=0.019)$. Higher exercise frequency $(>1$ times/day) was associated with further reduction in ODI compared to lower exercise frequency group (1 time/day) (22.09 \pm 19.09 vs. $7.38 \pm 12.58, p=0.017)$. There was no significant difference in ODI reduction between geriatric and nongeriatric participants $(p=0.24)$.
\end{abstract}

CONCLUSION: WFE improves functional symptoms of LBP regardless of age. This exercise could be implemented in a primary health-care setting in future to reduce the cost for LBP treatment.

\section{Introduction}

Low back pain (LBP) is a prevalent complaint in the productive and geriatric age group. The estimated global prevalence of LBP is about $31 \%$, and it is common in women aged 40-80 years old [1]. The prevalence of specific chronic LBP in Japan is $9.3 \%$ and of non-specific chronic LBP is $15.4 \%$ [2]. Meanwhile, in Thailand, the prevalence of LBP is $30 \%$, nearly the same with global prevalence [3]. In Indonesia, there was only one study regarding the prevalence of LBP. The prevalence of LBP among the productive age group was nearly $40 \%$ [4].

The disability caused by LBP is the highest compared to any other condition globally [1]. In the USA, more than 100 million USD is spent each year treating LBP. The most common treatments for LBP are pain medication with NSAID or oral/intra-articular steroid [5]. Other forms of treatment such as physiotherapy or physical exercise are still rarely advised to patients with LBP, especially to the elderly. About $75 \%$ of all LBP patients never get treatment other than oral medication.
Although physiotherapy had proven to reduce the economic burden of LBP by $20 \%$, it is regrettable that most general practitioner rarely recommends physiotherapy to treat LBP. The reluctance to prescribe physical activity stemmed from the lack of education regarding non-pharmaceutical therapy [6]. A systematic review regarding the cost-effective analysis of LBP therapy found that exercise or referral to such service by GPs may improve the cost-effectiveness of their treatment [7].

Among the available exercises, Williams flexion exercise (WFE) is one of the simplest and most commonly used physiotherapy exercises to treat LBP patients. It is proven to reduce pain and improve spinal range of motion (ROM) in LBP patients by strengthening the paraspinal muscles to support the degenerated facet joints [8].

Until now, there is no study regarding the application of physiotherapy exercise in Indonesia. Considering that WFE is the simplest and the most commonly used physiotherapy exercise, this study aims to evaluate the effect of WFE on people with LBP complaints. 


\section{Materials and Methods}

This study was a pretest-posttest experimental study design conducted in June-July 2018 in one of the primary health-care centers in Jombang city, East Java, Indonesia. Jombang is a small town and considered as a rural area in East Java. Participants of this study were PROLANIS program participants. PROLANIS is a program affiliated to Indonesian Universal Health Coverage to increase health promotion for patients with chronic disease such as type 2 diabetes mellitus and hypertension. The program holds a meeting every month with various activities, including health promotion, group physical activity, and medical check-up.

The total sampling method was used in this study. The inclusion criteria were PROLANIS participants with LBP symptoms who attended the meeting in June 2018. The exclusion criteria were malignancy of the spinal column or spinal cord or infection of the spinal area. Dropout criteria were PROLANIS participants who did not attend the meeting in July 2018 for follow-up evaluation or who did not do the WFE during the study period. In the session on June 2018, participants were given questionnaires consisting of two sections. The first section was regarding participants' characteristics and brief medical history. The second section was the Oswestry Disability Index (ODI) questionnaire. After filling out the questionnaire, participants were shown a video and live demonstration on how to do WFE. Pamphlets depicting the exercise were also given to each participant as a reminder if the participants forgot how to do the exercise in the correct way. In the next meeting on July 2018, participants were given ODI questionnaire again to evaluate the effect of WFE toward their LBP symptoms, and the participants were also asked to describe their WFE regularity in the past 1 month.

The patients were grouped as geriatric and non-geriatric with a cutoff age of 60 years old, as defined by the Indonesian government [9]. Participants' body mass index (BMI) was classified according to the WHOs Asian criteria [10]. ODI questionnaire final score ranges from $0 \%$ to $100 \%$, with following interpretations: $0 \%$ to $20 \%$ as minimal disability, $21 \%$ to $40 \%$ as moderate disability, $41 \%$ to $60 \%$ as severe disability, $61 \%$ to $80 \%$ as crippled, and $81 \%$ to $100 \%$ as bedbound/exaggerating [11].

This study followed the principles of the Declaration of Helsinki. All participants gave their informed consent before their inclusion in the study. Information was given before the participants signed the informed consent. Details that might disclose the identity of the participants were omitted.

Data were analyzed for its normality using the Shapiro-Wilk test. Paired $t$-test was used to compare ODI score pre- and post-WFE implementation. Independent $t$-test was used to compare ODI score
pre-WFE, post-WFE, and the $\Delta$ between pre- and post-WFE implementation between geriatric and nongeriatric groups. All statistical analyses were conducted using the SPSS Statistics for Windows version 25.0 (Armonk, NY: IBM Corp). $\mathrm{p}<0.05$ was considered statistically significant.

\section{Results}

There were 42 PROLANIS participants included in this study, but 4 participants dropped out because they did not do the WFE during the study period. At the end of the study period, there were a total of 38 participants. Nearly $90 \%$ of the participants were female. Geriatric age group comprised $62.9 \%$ of all participants. According to BMI status, around onethird of all participants were classified as normal. More than $70 \%$ of the participants only finished elementary school, and only $10 \%$ graduated from high school. Almost $80 \%$ of the patients were housewives. The most common comorbidity the participants had was hypertension followed by type 2 diabetes mellitus. Patients' demographic is depicted in Table 1.

Table 1: Subjects' demographic and clinical characteristics

\begin{tabular}{|c|c|}
\hline Clinical characteristics & $n=38 n(\%)$ \\
\hline \multicolumn{2}{|l|}{ Gender } \\
\hline Male & $4(10.5)$ \\
\hline Female & 34 (89.5) \\
\hline \multicolumn{2}{|l|}{ Ages (years) } \\
\hline \multicolumn{2}{|l|}{ Non-geriatric } \\
\hline $40-49$ & $3(7.9)$ \\
\hline $50-59$ & $10(26.3)$ \\
\hline \multicolumn{2}{|l|}{ Geriatric } \\
\hline $60-69$ & $16(42.1)$ \\
\hline $70-79$ & $8(21.1)$ \\
\hline$\geq 80$ & $1(2.6)$ \\
\hline \multicolumn{2}{|l|}{ BMI (Asian criteria) } \\
\hline <18.5 (Underweight) & $5(13.2)$ \\
\hline 18.5-22.9 (Normal) & $13(34.2)$ \\
\hline 23-27.49 (Overweight) & $10(26.3)$ \\
\hline$\geq 27.5$ (Obese) & $7(18.4)$ \\
\hline No data & $3(7.1)$ \\
\hline \multicolumn{2}{|l|}{ Education attainment } \\
\hline No education & $3(7.9)$ \\
\hline Elementary school & $28(73.7)$ \\
\hline Junior high school & $3(7.9)$ \\
\hline Senior high school & $3(7.9)$ \\
\hline Diploma & $1(2.6)$ \\
\hline \multicolumn{2}{|l|}{ Occupation } \\
\hline Farmer & $3(7.9)$ \\
\hline Teacher & $1(2.6)$ \\
\hline Entrepreneur & $5(13.2)$ \\
\hline Housewife & $29(76.3)$ \\
\hline \multicolumn{2}{|l|}{ Comorbidities } \\
\hline Diabetes mellitus & $9(23.7)$ \\
\hline Hypertension & $19(50)$ \\
\hline Dyslipidemia & $5(13.2)$ \\
\hline Asthma & $1(2.6)$ \\
\hline CVA & $1(2.6)$ \\
\hline Gout & $1(2.6)$ \\
\hline
\end{tabular}

The pre-WFE ODI score (acquired from PROLANIS meeting in June 2018) showed that almost $50 \%$ of the participants had a moderate disability due to LBP. There were two patients classified as crippled. After 1 month (in July 2018), there was no participant with severe disability or worse. ODI score post-WFE implementation was significantly lower compared to pre-WFE implementation (31.05 \pm 17.40 vs. $14.10 \pm$ 
11.78, $\mathrm{p}<0.001)$. The comparison of the ODI score before and after exercise is depicted in Table 2.

Table 2: The effect of WFE toward ODI reduction

\begin{tabular}{llll}
\hline ODI score (\%) & Pre-WFE n=38 n (\%) & Post-WFE n=38 n (\%) & p-value \\
\hline $0-20$ & $9(23.7)$ & $27(71.1)$ & $0.019^{* *}$ \\
$21-40$ & $19(50.0)$ & $11(28.9)$ & \\
$41-60$ & $8(21.1)$ & $0(0)$ & \\
$61-80$ & $2(5.3)$ & $0(0)$ & \\
$81-100$ & $0(0)$ & $0(0)$ & \\
(Mean $\pm S D)$ & $31.05 \pm 17.40$ & $14.11 \pm 11.78$ & \\
"Paired $t$-test was used. ${ }^{*}<0.05$ was considered significant. ODI: Oswestry Disability Index, WFE: Williams \\
flexion exercise.
\end{tabular}

Both geriatric and non-geriatric groups had a significant difference between pre- and post-WFE ODI score (35.20 \pm 18.32 vs. $16.32 \pm 11.25, p<0.001 ; 23.08$ \pm 12.56 vs. $9.85 \pm 12.04, p=0.002$, respectively). There was no significant difference between $\Delta$ ODI scores in the geriatric and non-geriatric groups (18.40 \pm 20.43 vs. $11.08 \pm 11.42, p=0.24)$. The comparison is depicted in Table 3.

Table 3: The effect of WFE toward ODI reduction between geriatric and non-geriatric age groups

\begin{tabular}{|c|c|c|c|c|c|c|}
\hline Age group & $\begin{array}{l}n=38 \\
n(\%)\end{array}$ & $\begin{array}{l}\text { Pre-WFE ODI } \\
(m e a n \pm S D)\end{array}$ & $\begin{array}{l}\text { Post-WFE ODI } \\
\text { (mean } \pm S D \text { ) }\end{array}$ & $\mathrm{p}$-value & $\begin{array}{l}\Delta \mathrm{ODI} \\
(\text { mean } \pm \mathrm{SD})\end{array}$ & $p$-value \\
\hline Geriatric & $25(65.79)$ & $35.20 \pm 18.32$ & $16.32 \pm 11.25$ & $<0.001^{1 *}$ & $18.40 \pm 20.43$ & $0.24^{t}$ \\
\hline Non-geriatric & $13(34.21)$ & $23.08 \pm 12.56$ & $9.85 \pm 12.04$ & $0.002^{t_{*}}$ & $11.08 \pm 11.42$ & \\
\hline
\end{tabular}

In the group who exercised only 1 time/day, there was a significant improvement of ODI score, $27.13 \pm 16.13$ before exercise compared to $19.00 \pm$ 11.38 after exercise $(p=0.0017)$. There was also a significant improvement in those who exercised $>1$ times/day $(p<0.001)$. Their ODI had decreased from $33.90 \pm 18.09$ before exercise to $10.55 \pm 10.97$ after. A more significant reduction was observed in those who exercised $>1$ times/day compared to those who exercised only 1 time/day $(p=0.011)$. The results are presented in Table 4.

Table 4: Correlation between exercise frequency and ODI reduction

\begin{tabular}{lllllll}
\hline $\begin{array}{l}\text { Exercise } \\
\text { frequency }\end{array}$ & $\begin{array}{l}\mathrm{n}=38 \\
\mathrm{n}(\%)\end{array}$ & $\begin{array}{l}\text { Pre-WFE ODI } \\
(\text { mean } \pm \mathrm{SD})\end{array}$ & $\begin{array}{l}\text { Post-WFE ODI } \\
(\mathrm{mean} \pm \mathrm{SD})\end{array}$ & $\mathrm{p}$-value & $\begin{array}{l}\Delta \text { ODI } \\
(\text { mean } \pm S \mathrm{SD})\end{array}$ & $\mathrm{p}$-value \\
\hline 1 time/day & $16(38.1)$ & $27.13 \pm 16.13$ & $19.00 \pm 11.38$ & $0.017^{* *}$ & $7.38 \pm 12.58$ & $0.011^{1 *}$ \\
$>1$ times/day & $22(52.38)$ & $33.90 \pm 18.09$ & $10.55 \pm 10.97$ & $<0.001^{* *}$ & $22.09 \pm 19.10$ & \\
\hline
\end{tabular}

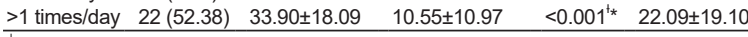

'Paired $t$-test was used. ${ }^{*}<0.05$ was considered significant. ODI: Oswestry Disability Index, WFE: Williams flexion exercise.

\section{Discussion}

In our study, nearly $90 \%$ of the participants who complained of LBP were female. A recent literature review noted that the prevalence of LBP in females is generally higher than males across all age groups, and it continues to increase after menopause [12]. In rural Korea, the same result was observed, and the LBP severity is correlated to the degree of lumbar spondylosis [13]. However, we did not evaluate the exact etiology of LBP in our study.

More than $50 \%$ of our participants were overweight or obese according to the Asian criteria.
Several studies have pointed out that higher BMI and low height are associated with the prevalence and severity of LBP [14]. Other than the increased axial load of the spine in case of high BMI, a high degree of adiposity was shown to increase the level of adipokines which may increase the rate of intervertebral degeneration causing LBP [15]. Furthermore, adipokines increased the risk of a mood disorder like depression which may affect the severity of chronic pain such as LBP [16].

Most of our participants had low educational status. Lower education and socioeconomic status are associated with more severe LBP complain. The mechanism behind the connection between lower formal education level and LBP is that a low education leads to a worse adaptation mechanism to illness [17].

Hypertension was the most common comorbidity found in our participants. There are two conflicting views regarding the correlation between hypertension and chronic pain like LBP. Bruehl et al. suggested that chronic pain is associated with increased risk of hypertension [18]. However, a Korean study found that the prevalence of chronic pain, including LBP, is lower in hypertensive patients due to hypertensionassociated hypoalgesia. Hypertensive medications have shown to increase this phenomenon [19].

Diabetes mellitus was also found in about onefourth of our participants. A Spanish study on twins found a positive correlation between type 2 diabetes mellitus and LBP in their cross-sectional analysis. The study suggested that there might be a common risk factor ascribed to both diseases because the causal relationship only observed when confounding factors are controlled [20].

Our study found that the implementation of WFE positively affects LBP complaint among PROLANIS participants, marked with a significant reduction of ODI score on the $2^{\text {nd }}$ meeting. The previous research found a similar result that WFE improved pain complaints and spinal ROM in their participants [8]. The principles of WFE are facilitating lumbar flexion and strengthening abdominal and gluteal muscles to alleviate LBP symptoms. Facilitation of lumbar flexion would widen the intervertebral foramina and stretch the extensor muscles of the spine and the facet joints. The exercises suggested by Williams are as follows: Pelvic tilt, partial sit-ups, single and bilateral knee to chest, hamstring stretch, lunges, seated trunk flexion, and full squats [21]. Spinal flexion itself is safe; it may even increase intervertebral disc strength with proper regiment [22]. Another study also agreed that WFE decreases pain and increases spinal ROM, but it concluded that selective Pilates exercise is more beneficial compared to WFE in those regards [23]. Further study is compulsory to assess more alternative exercises to tackle this chronic pain problem.

Comparing the geriatric and non-geriatric groups in our study, there was a significant difference 
in regard to the initial ODI score. LBP complaint in older adults is generally more complex compared to their younger counterparts. More severe LBP is correlated to advanced age. Confounding factor such as dementia and psychosocial factor may play a role in pain perception. Thus, the management of LBP in geriatric patients requires deeper and multimodal considerations [24]. However, there was no difference in ODI decrease of both groups and in the after exercise ODI. This may indicate that WFE is equally effective for both geriatric and non-geriatric participants. To the best of our knowledge, there is no previous study that compares the effect of WFE in geriatric and nongeriatric groups.

We found that higher exercise frequency was associated with greater reduction of ODI score. This result is supported by several other studies. Hashimoto et al. found that objectively measured physical activity is negatively correlated to LBP [25]. Lee and Kang also stated that the combination of walking and strength exercise might improve LBP symptoms [26]. The effects of other forms of exercise, including walking, should be explored further in future studies.

Our study has some limitations, including the low number of sample and short study period. However, in our knowledge, this is the first study in Indonesia which assess the possible implementation of WF exercise to alleviate LBP complain in a rural population in Indonesia. Further research with a larger sample and more extended study period are needed to evaluate more aspects regarding this topic. Furthermore, there should be more studies regarding how to increase the implementation of WFE and other types of exercise among the target population effectively.

\section{Conclusion}

WFE is proven to alleviate functional symptoms in LBP patients regardless of patients age. The more the exercise frequency, the better the ODI score outcome. Future implementation of this exercise among the population in the primary health-care center can be considered.

\section{References}

1. Hoy D, Bain C, Williams G, March L, Brooks P, Blyth F, et al. A systematic review of the global prevalence of low back pain. Arthritis Rheum. 2012;64(6):2028-37. https://doi.org/10.1002/ art.34347

PMid:22231424
2. lizuka $\mathrm{Y}$, lizuka $\mathrm{H}$, Mieda $\mathrm{T}$, Tsunoda $\mathrm{D}$, Sasaki $\mathrm{T}$, Tajika $\mathrm{T}$, et al. Prevalence of chronic nonspecific low back pain and its associated factors among middle-aged and elderly people: An analysis based on data from a musculoskeletal examination in Japan. Asian Spine J. 2017;11(6):989-97. https://doi. org/10.4184/asj.2017.11.6.989

PMid:29279756

3. Yiengprugsawan $V$, Hoy $D$, Buchbinder $R$, Bain $C$ Seubsman SA, Sleigh AC. Low back pain and limitations of daily living in Asia: Longitudinal findings in the Thai cohort study. BMC Musculoskelet Disord [Internet]. 2017;18(1):1-7. https:// doi.org/10.1186/s12891-016-1380-5

PMid:28103864

4. Sadeli HA, Sofiatin Y, Roesli RMA, Sukandar H, Novitasari DD, Soenggono A. Prevalence and Characteristics of Low Back Pain among Productive Age Population in Jatinangor. Althea Med J. 2017;3(3):469-76. https://doi.org/10.15850/amj.v3n3.863

5. Allegri M, Montella S, Salici F, Valente A, Marchesini M, Compagnone $\mathrm{C}$, et al. Mechanisms of low back pain: a guide for diagnosis and therapy. F1000Research [Internet]. 2016;5:1530. https://doi. org/10.12688/f1000research.8105.1 PMid:27408698

6. Persson G, Brorsson A, Hansson EE, Troein M, Strandberg EL. Physical activity on prescription (PAP) from the general practitioner's perspective - a qualitative study. BMC Fam Pract [Internet]. 2013;14(1):1. https://doi. org/10.1186/1471-2296-14-128

PMid:23987804

7. Lin CWC, Haas M, Maher CG, MacHado LAC, Van Tulder MW. Cost-effectiveness of general practice care for low back pain: A systematic review. Eur Spine J. 2011;20(7):1012-23. https:// doi.org/10.1007/s00586-010-1675-4

PMid:21203890

8. Mohan G. Effectiveness of William's Flexion Exercise in the Management of Low Back Pain. Int J Physiother Occup Ther. 2015;1:33-40.

9. Kementrian Kesehatan Republik Indonesia. Situasi dan Analisis Lanjut Usia [Situation and Analysis of the Elderly]. Jakarta;2014. p. 1. https:// doi.org/10.6066/jtip.2013.24.2.121

10. WHO Expert Consultation. Appropriate body-mass index for Asian populations and its implications for policy and intervention strategies. Lancet (London, England). 2004 Jan;363(9403):15763. https://doi. org/10.1016/s0140-6736(03)15268-3 PMid:24551438

11. Fairbank JC, Pynsent PB. The Oswestry Disability Index. Spine (Phila Pa 1976). 2000 Nov;25(22):2940-52. https://doi. org/10.1097/00007632-200011150-00017 PMid:11074683

12. Wáng $Y X$, Wáng JQ, Káplár $Z$. Increased low back pain prevalence in females than in males after menopause age: evidences based on synthetic literature review. Quant Imaging Med Surg. 2016;6(2):199-206. https://doi.org/10.21037/ qims.2016.04.06 PMid:27190772

13. Lee SY, Cho NH, Jung YO, Seo Y II, et al. Prevalence and Risk Factors for Lumbar Spondylosis and Its Association with Low Back Pain among Rural Korean Residents. J Korean Neurosurg Soc. 2017;60(1):67-74. https://doi.org/10.3340/ jkns.2016.0505.007 PMid:28061494

14. Chowdhury D, Sarkar S, Rashid MH, Rahaman A, Sarkar SK, Roy R. Influence of body mass index on low back pain. Mymensingh Med J. 2014 Jan;23(1):125-9. PMid:24584385

15. Sharma A. The Role of Adipokines in Intervertebral Disc 
Degeneration. Med Sci (Basel). 2018;6(2):34. https://doi.org/ HYPERLINK "https://doi.org/10.3390/medsci6020034"10.3390/ medsci6020034

PMid:29695079

16. Chou L, Brady SR, Urquhart DM, et al. The Association Between Obesity and Low Back Pain and Disability Is Affected by Mood Disorders: A Population-Based, Cross-Sectional Study of Men. Medicine (Baltimore). 2016;95(15):e3367. https://doi. org/10.1097/ md.0000000000003367

PMid:27082599

17. Dionne CE, Von Korff M, Koepsell TD, Deyo RA, Barlow WE, Checkoway $\mathrm{H}$. Formal education and back pain: a review. $J$ Epidemiol Community Health. 2001;55(7):455-68. https://doi. org/ 10.1136/jech.55.7.455

PMid: 11413174

18. Bruehl S, Chung OY, Jirjis JN, Biridepalli S. Prevalence of clinical hypertension in patients with chronic pain compared to nonpain general medical patients. Clin J Pain. 2005;21(2):14753. https:// doi.org/10.1097/00002508-200503000-00006 PMid:15722808

19. Bae Y, Shin J, Lee J, Kim M, Park KB. Association between Hypertension and the Prevalence of Low Back Pain and Osteoarthritis in Koreans: A Cross-Sectional Study. HYPERLINK "https://www.ncbi.nlm.nih.gov/pubmed/26393797"PLoS One. 2015 Sep 22;10(9):e0138790. https://doi.org/10.1371/journal. pone. 0138790

PMid:26393797

20. Dario A, Ferreira M, Refshauge K, Harmer A, Sanchez-Romera $\mathrm{J}$, Perez-Riquelme $\mathrm{F}$, et al. Mapping the association between back pain and type 2 diabetes: A cross-sectional and longitudinal study of adult Spanish twins. PLoS One. 2017;12(4):1-15. https://doi.org/10.1371/journal.pone.0174757

\section{PMid:28369107}

21. Houglum PA. Strength Exercises for the Lower Back, Abdomen, and Pelvis. In: Houglum PA. Therapeutic Exercise for Musculoskeletal Injuries, Champaign, IL: Human Kinetics;2005. p. 610-2.

22. Contreras B, Schoenfeld BJ. AC To Crunch or Not to Crunch: An Evidence-Based Examination of Spinal Flexion Exercises. Strength and Conditioning J. 2011;33(4):8-18. https://doi. org/10.1519/ssc.0b013e3182259d05

23. Fallahzadeh R, Pirouzi S, Taghizadeh S. The Comparison of the Effects of Selective Pilates and Williams' Exercises on Pain and Flexibility in Men with Chronic Non-Specific Low Back Pain : A Randomized Clinical Trial. J Rehabil Sci Res. 2016;4(2015):87-92. https://doi.org/ 10.30476/JRSR.2015.41081

24. Wong AY, Karppinen J, Samartzis D. Low back pain in older adults: risk factors, management options and future directions. Scoliosis Spinal Disord. 2017;12:14. https://doi.org/10.1186/ s13013-017-0121-3 PMid:28435906

25. Hashimoto Y, Matsudaira K, Sawada SS, Gando Y, Kawakami R, Kinugawa $\mathrm{C}$, et al. Objectively Measured Physical Activity and Low Back Pain in Japanese Men. J Phys Act Health. 2018 Jun;15(6):417-22. https://doi.org/10.1123/jpah.2017-0085 PMid:29542388

26. Lee JS, Kang SJ. The effects of strength exercise and walking on lumbar function, pain level, and body composition in chronic back pain patients. J Exerc Rehabil. 2016;12(5):463-70. https:// doi.org/10.12965/jer.1632650.325

PMid:27807526 